\title{
Care leaders' experiences of collaboration between healthcare professions in primary care: an explorative qualitative study
}

Jessica Hemberg ( $\nabla$ jessica.hemberg@abo.fi )

Åbo Akademi University

Jasmina Nyberg

Åbo Akademi University

\section{Research Article}

Keywords: care leaders, collaboration, experiences, healthcare, interviews

Posted Date: February 23rd, 2022

DOI: https://doi.org/10.21203/rs.3.rs-1302207/v1

License: (c) (i) This work is licensed under a Creative Commons Attribution 4.0 International License.

Read Full License 


\section{Abstract}

Background: The need for interprofessional collaboration in increasing, because a single professional group can no longer meet patients' increasingly complex and multifaceted health-related problems and needs. Researchers have found that effective interprofessional collaboration is needed, especially in primary care. The aim of the study was to explore care leaders' experiences of collaboration between different healthcare professions in primary care.

Methods: An explorative qualitative design and qualitative content analysis were used. Data were collected in February and March 2021. The data material consists of texts from interviews with care leaders working in outpatient care in a primary care setting. The method was inspired by content analysis.

Results: Six main themes emerged: Physically close interaction, inclusion of clients and understanding clients' individual needs; Quick flow of communication, participation and common approach; Inclusion of other professions and sectors, and non-hierarchical work; Capacity for interaction and cooperation, respect for others' knowledge, commitment to change and utilization of potential; Purposeful action, enablement of developmental work and boundary-crossing work; Commitment of management, prioritization, structured action, justification and clear division of work.

Conclusions: Care leaders experience the development and implementation of effective collaboration between different healthcare professions to be important and necessary in primary care. Factors considered to promote interprofessional collaboration are physically close interaction, inclusion of clients, understanding clients' individual needs, quick flow of communication, participation and common approach, inclusion of other professions and sectors, and non-hierarchical work. Factors important to the development of collaboration are capacity for interaction and cooperation, understanding and respect for others' knowledge, commitment to change, utilization of potential, purposeful action, enablement of developmental work, boundary-crossing work, commitment of management and the organization, prioritization, structured action, justification and clear division of work and responsibility. A focus on collaboration between different professions in other healthcare sectors could be included in future research.

Trial registration: Registration for the study made by an ethical committé $1^{\text {st }}$ January 2021.

\section{Background}

To meet the changes occurring in the challenging context of healthcare, greater focus in some countries is being placed on interprofessional collaboration and the development of interprofessional teams (1). A single professional group can no longer meet patients' increasingly complex and multifaceted healthrelated problems and needs; instead, interprofessional collaboration is needed (2). The World Health Organization also emphasizes the importance of implementing interprofessional learning and collaboration in all healthcare services offered, with the aim to improve health outcomes and respond to 
challenges in healthcare systems (3). In Finland, collaboration between different occupational groups and the division of labor so as to develop and ensure efficiency and continuity of care, efficient care pathways, service and cost management are delineated in the current Finnish Government's Government Program (4). Furthermore, over the past decade efforts have been made to plan and realize integrated social and healthcare services in Finland, with the goal of creating a more coherent entity (5).

Interprofessional collaboration in a healthcare setting is important for the realization of a holistic view, a viable work network, person-centeredness, equality, flexible collaboration and staff well-being (6). A lack of collaborative skills between professions or occupational groups can result in negative consequences, e.g., low patient safety, unfavorable outcomes $(7,8)$, obstacles to person-centered care (9) or even patient injury or care errors $(10,2)$. Effective collaboration, meanwhile, has been linked to positive patient outcomes (8), high care quality and patient safety $(11,12,10,13)$. Researchers have also seen that patients can perceive receiving conflicting information from doctors and/or other healthcare professionals to be concerning (14). Though discussed, research on interprofessional collaboration remains limited (5). A humane and qualitative care presupposes close cooperation and joint quality control (5). As care becomes more complex and specialized, more effective communication and collaboration is needed to be able to offer patients the best possible care (10). The need for collaboration between different healthcare professions is particularly pronounced in primary care, because patients' care needs in primary care vary greatly $(15,16)$. Interprofessional primary care teams improve healthcare systems and promote positive patient outcomes, especially for patients with complex care needs (1). Many different concepts and terms are associated with interprofessional collaboration. The terms interprofessional, multiprofessional and interdisciplinary are often used synonymously, even if differences exist between these terms' meanings (17). In what can be considered a "traditional approach", in multiprofessional and multidisciplinary work several disciplines work in parallel rather than in interaction with each other to meet patients' care needs (17). This differs from what can be considered a "modern approach", that is interprofessional and interdisciplinary collaboration characterized by various professions interacting with one another in pursuit of common goals through joint planning, close communication and shared responsibility (17). In a meta-analysis, Petri (18) defined interprofessional collaboration as a problem-focusing process in which health care professionals from different disciplines work together with a non-hierarchical structure for a common goal for solving problems in patient care. In the term interprofessional, the prefix inter- can be said to reference an adaptation of roles, knowledge, skills and responsibilities. Also, the importance of a common time and place for the exchange of information is highlighted in an interprofessional approach (6). Different healthcare professionals from various professional areas are included in an interprofessional team, because several experts can facilitate the identification of problems and formulation of possible solutions (5). The composition of a healthcare team varies, relevant to a patient's needs and the team's task, and a team can include, e.g., doctors, nurses, pharmacists, physiotherapists, occupational therapists and/or social workers (8). Interprofessional collaboration is recommended as a comprehensive approach whereby care teams can ensure person-centered care by combining skills, experience and knowledge (13). Interprofessional collaboration involves regular negotiation and interaction between team members (12), where all team members support and trust one another and the result depends on how committed team members are to 
collaboration (5). Interprofessional collaboration and coordination are key elements in an interprofessional approach (8) and can be implemented in different healthcare contexts, from older adult to acute care (13). Elements necessary for interprofessional collaboration are interprofessional learning, role awareness, interpersonal skills, conscious action and support (18). Interprofessional collaboration entails understanding and valuing other professions, understanding own and others' roles and responsibilities, having mutual respect, trust and open communication between team members (18). Also important are intentional measures, team-building skills, relationships, the ability to work together, and support for collaboration on the individual and organizational levels (18). The goal of interprofessional collaboration is to ensure a responsive and integrated approach to care through a focus on clients' needs (19). According to Youngwerth and Twaddle (13), interprofessional collaboration is based on synergy, interdependence and interaction between team members, where each team member has special expertise and works with the other team members to achieve common goals. An interprofessional approach allows for the consideration of professionalism in care teams, instead of a focus on the individual professional group's professionalism (20). Moreover, patients expect to receive care from interprofessional care teams (8). Interprofessional collaboration improves clinical care outcomes, care processes and satisfaction, increases patient safety, organizational commitment and productivity, and reduces older people's incidence of falls and related injuries (13). Good communication and good collaboration between several healthcare professions strengthen healthcare systems (1) and reduce hospital stays and healthcare costs (13). Effective professional-patient healthcare interaction as well as effective communication and coordination between healthcare professionals and the continuous development of collaboration are needed to realize good collaboration (21). Several factors are important for the realization of a functioning interprofessional team. To respond to the changing healthcare environment, healthcare teams must be dynamic (1). Effective collaboration depends on communication, interpersonal relationships, team structure and coordination, and organizational factors $(13,14)$. Of these, communication is the most important element (14) and requires an active exchange of information in both formal and informal ways $(13,14,21)$. Formal communication takes place in regular, interprofessional team meetings through an active exchange of information and is important not only for patient assessment but also for the promotion of positive interpersonal relationships, conflict resolution and the improvement of team collaboration and communication $(14,8,13)$. Formal team meetings can take the form of regularly occurring bedside rounds or organized meetings where the patient and patient's family are included in goal-directed collaboration (14). Various factors can negatively affect interprofessional collaboration. Conflicts between different professions often occur, especially in primary care (16). A lack of communication leads to ineffective collaboration and/or tension and can have negative consequences for patient safety $(10,8,11,14)$. A lack of communication is the leading cause of patient injury and can prevent a team from collaborating and providing person-centered care $(13,14)$. Communication problems can lead to coordination problems; complex work requires a division of labor, coordination, integration and delegation (11). To realize collaboration between different professions, healthcare professionals need the support of management and an understanding of (others') practice (15). Weller et al. (10) found that each professional group has its own special way of working within its own discipline and that when working in a team each group subsequently has different expectations of 
the content, structure and transfer of information. Therefore, it is important to emphasize leadership in relation to coordination and planning within a team as well as team development, motivation and the creation of a positive atmosphere. Problems related to role "boundary" conflicts or a lack of clear role distribution and/or division of responsibilities can also negatively affect interprofessional collaboration $(16,12,11,14,13)$. One of the most common obstacles to effective collaboration is linked to not understanding others' roles and/or importance in an interprofessional team, i.e., a lack of understanding of what other professionals do in practice alongside an unclear division of responsibilities within the team (16). Although to some extent interprofessional teams can benefit from overlapping roles, misunderstandings can arise when team members exceed their professional boundaries because of an unclear division of responsibilities $(11,14)$. How professionals understand others' roles, responsibilities and priorities are linked to interdisciplinary differences and differences in education, and these can give rise to interprofessional conflicts and thus become an obstacle for interprofessional teams (10). Twaddle (14) emphasized that the majority of healthcare professionals have not learned how to work in interdisciplinary and/or interprofessional teams during their training. Therefore, to inhibit misunderstandings it is extremely important that conflict resolution skills be developed and regular team meetings be held in which there is focus on communication skills. Effective interprofessional collaboration is needed $(2,10,13,19,22)$, especially in primary care $(15,16)$. However, research on the topic in a primary care setting is lacking $(15,23)$. In previous studies, researchers have placed a general focus on collaboration between different occupational groups $(20,7,23,1,18,12,11,15,21,10,13)$ or on cooperation between different professional groups from various points of view: professionals $(22,16)$, professionals and managers (24), professionals and patients (8), healthcare students $(25,2)$, or healthcare teachers and faculty (26). Collaboration in healthcare, especially interprofessional collaboration, is an important and timely topic. Yet the concept itself has not been fully investigated.

There are few studies in which care leaders' points of view on collaboration have been examined, and few in primary care. In most studies, acute care environments (23) or collaboration between groups in different surgical and acute medical teams have been investigated (11). Consequently, there is a shortage of studies in primary care $(15,16,23)$.

\section{Methods}

The aim of this study was to gain an understanding of care leaders' experiences of collaboration between different healthcare professions in primary care. The research questions were: How do care leaders in primary care experience collaboration between different healthcare professions? Which needs and possibilities for development do care leaders experience exist in relation to improving collaboration between different healthcare professions? The study has a qualitative design, and the method was inspired by content analysis (27). The data material consists of texts from interviews with care leaders working in outpatient care in a primary care setting.

\section{Data material and data collection}


The data material was collected through individual interviews with five care leaders (aged 32-58, all females) in primary care in Finland. During the interviews, the participants were asked about their experiences of interprofessional collaboration between different healthcare professions in primary care. The participants' work experience as care leaders varied from one to 13 years. They had similar middleclass socioeconomic backgrounds and came from an urban area in the south of Finland.

The participants were recruited by email and telephone. The person in charge of outpatient care in the primary care setting included in this study acted as a contact person and recommended suitable professionals. An information letter about the study and participation was sent by email to all those recommended. Afterwards, the first author contacted the prospective participants by telephone to provide more detailed information about the study, which was given both orally and (later) in writing. Those who agreed to participate were scheduled for an interview.

An interview guide was drawn up in close collaboration between both researchers. The interview guide themes included, e.g., how care leaders experience interprofessional collaboration, their views on how such collaboration could be developed, and the needs they perceived existed related to the development of collaboration. Due to the COVID-19 pandemic, the semi-structured interviews were conducted digitally via Microsoft Teams during February and March 2021. The interviews lasted between 30-60 minutes and were recorded and transcribed verbatim.

\section{Analysis}

The data material was analyzed using qualitative content analysis (27). The texts from the interviews were read several times by both researchers with openness. Sentence units were color highlighted and thereafter condensed, coded and categorized. Six main themes emerged from the analysis, with the researchers discussing and agreeing on the final themes. See Table 1 for an example of the data analysis.

Table 1

An example of the data analysis. 


\begin{tabular}{|c|c|c|c|c|}
\hline Meaning unit & $\begin{array}{l}\text { Condensed } \\
\text { meaning unit }\end{array}$ & Code & Category & Main theme \\
\hline $\begin{array}{l}\text { Collaboration between } \\
\text { different healthcare } \\
\text { professions means to } \\
\text { me that... it is easy and } \\
\text { quick to consult and } \\
\text { ask, to consider things }\end{array}$ & $\begin{array}{l}\text { Quick and easy } \\
\text { consultation }\end{array}$ & $\begin{array}{l}\text { Effective } \\
\text { collaboration } \\
\text { requires quick } \\
\text { and easy } \\
\text { communication }\end{array}$ & \multirow[t]{2}{*}{$\begin{array}{l}\text { Effective } \\
\text { collaboration } \\
\text { requires } \\
\text { effective } \\
\text { communication }\end{array}$} & \multirow[t]{2}{*}{$\begin{array}{l}\text { Quick flow of } \\
\text { communication, } \\
\text { participation } \\
\text { and common } \\
\text { approach }\end{array}$} \\
\hline $\begin{array}{l}\text { Continuous } \\
\text { communication.... is } \\
\text { the only way to in } \\
\text { some way [make it } \\
\text { work] with the } \\
\text { interprofessional team } \\
\text { or on the whole [get] } \\
\text { information to move... } \\
\text { it must get started }\end{array}$ & $\begin{array}{l}\text { Continuous } \\
\text { communication } \\
\text { enables the } \\
\text { exchange of } \\
\text { information } \\
\text { during } \\
\text { collaboration }\end{array}$ & $\begin{array}{l}\text { Mutual } \\
\text { communication } \\
\text { enables } \\
\text { collaboration }\end{array}$ & & \\
\hline
\end{tabular}

\section{Ethical considerations}

Good scientific practice has been followed during the course of this research, and it has been conducted in accordance with the guidelines for the Finnish National Board on Research Integrity TENK (28). One of the researchers contacted those care leaders recommended for participation in the study by email and telephone. The care leaders received both oral and written information about the study purpose, voluntary participation, confidentiality and the intention to publish the study results. Informed consent was obtained from the study participants. Ethical approval was obtained (January 4,2021) from an ethical committé in the joint municipality in the southern of Finland where the interviews were conducted.

\section{Results}

Six main themes emerged, described in more detail below (see Table 2).

Table 2

Study findings. 
Physically close interaction, inclusion of clients and understanding clients' individual needs

Quick flow of communication, participation and common approach

Inclusion of other professions and sectors, and non-hierarchical work

Capacity for interaction and cooperation, respect for others' knowledge, commitment to change and utilization of potential

Purposeful action, enablement of developmental work and boundary-crossing work

Commitment of management, prioritization, structured action, justification and clear division of work

\section{Physically close interaction, inclusion of clients and understanding clients' individual needs}

A need exists to understand the work of other professionals. "... occupational groups are quite awfully separated from one another, are not familiar with one another's work. The work that they tangibly do, that is to say they should also be combined so that we get started a greater amount of information" (P2).

Physically close interaction promotes a functional collaboration that enables the exchange of information and reduces communication difficulties. "... this previous idea that work partners working in their own rooms... the exchange of information does not occur then" (P3) and "... it in some way complicates communication when you are in different buildings and are further away" (P4).

The inclusion of clients and understanding of their individual needs is central to promoting collaboration. "Especially in primary care, you must think about who it is who is using our services... that is to say how you really start immediately guiding these patients to the right professional groups" (P3). A holistic view of clients and a broader perspective are needed to address clients' diverse care needs, which in turn requires collaboration with different healthcare professions.

"Because things are often... especially if it is about a multi-problematic person who uses a lot of services at a healthcare center... it often happens that he/she for example has substance abuse problems and then help is needed for that as well. There are complex cases" (P1).

"It is no longer the case that there is a problem with the left ear but instead the client is a whole, if you want to provide care it does not succeed without collaboration with different healthcare professions... I 


\section{Quick flow of communication, participation and common approach}

The quick and functional flow of communication between different actors is important for the sharing of knowledge and information. "Collaboration between different healthcare professions means to me that... it is easy and quick to consult and ask, to consider things" (P1).

"... we have aimed for quick communication... it is very tiring if you are not used to such continuous communication but it is the only way to in some way [make it work] with the interprofessional team or on the whole [get] information to move... it must get started" (P3).

Inclusion leads to participation, which promotes collaboration. Allowing caregivers to collaborate and feel like important actors in a larger context allows caregivers to present their perspective on a matter and their knowledge. "I think it is important to do it together so that there does not only come dictated instructions that now you do this like this..." (P1) "... it presupposes that the team includes the members who should belong to it and that all resources are used" (P3).

"...at best the collaboration between different healthcare professions has been that we have had all the staff involved in developing... where the staff have gotten to say their own perspective... what helps is to do together with everyone, even if some are not so enthusiastic" (P2).

A common approach also facilitates collaboration. "...there should be common approaches and rules for everyone" (P2) "I miss it more... such purposeful movement in a direction toward that we have [things in common]" (P5).

\section{Inclusion of other professions and sectors, and non- hierarchical work}

A need for the inclusion of various other professions and sectors in collaboration was revealed.

"Of course the wider the team is and of course the more different people there are, different professions, the better... you should bring together different professions to get a greater amount of information to continue on" (P1).

Another participant stated:

"...we have a lot of specialization and sometimes we cannot utilize the right profession in handling the matter... that we ourselves try to do when there is an expert somewhere else but how can you utilize that 
knowledge when we do not know it... professionals who are not in the team remain a little unfamiliar. And then making the most of the situation deteriorates" (P4).

Collaboration also entails more than working within one's own team. "... I see collaboration between different healthcare professions [as being] much broader than [within] your own team" (P2). More collaboration between mental health, social and substance abuse care services was highlighted.

"We still lack mental health and social services... the support for the team... that we get integrated mental health services, the survival of primary care is otherwise impossible" (P3). "But there is a lot in healthcare that you do not know exists for example knowledge about substance abuse care..." (P4).

The participants mentioned that major changes have occurred over the years and sought to further emphasize the importance of non-hierarchical work as something that promotes collaboration between professions. "... there is no longer such a hierarchical work as there used to be" (P1). "...you are in completely different spheres even if [previously] there was cooperation between different healthcare professions but it is probably so much closer and such... low hierarchical" (P3). Non-hierarchical work has several benefits.

"... if it is traditional top-down leadership then you really do not get the staff involved in any way ... hierarchical leadership leads to the management not hearing what the staff say, mistakes are easily made, setbacks to development projects" (P2).

\section{Capacity for interaction and cooperation, respect for others' knowledge, commitment to change and utilization of potential}

The capacity for interaction and cooperation is needed to develop understanding of the importance of teamwork and thus collaboration. "... it presupposes the capacity for interaction ..." (P4). Another participant said:

"It takes understanding of that we are not here to work alone or that this is just my thing but instead this is our common [thing]... to understand that we work as a team... this is not just your work list or your patient but instead it is the team's common... the idea of a team emanates in some way already from [one's] educational background..." (P3).

Respect and understanding for others' knowledge was strongly emphasized as an important component for the development of collaboration. "All professions are needed but more so that we understand what each can give to exactly that moment ... or to a certain situation" (P3). "It presupposes mutual trust between professionals. That you appreciate and trust others' expertise" (P4). Sharing knowledge with one another was considered enriching. 
"... the fact that you probably will get a lot more out of it when there are perspectives from different areas... and gives faith that if we share information or knowledge and take courageous responsibility for other people's domains so I think it will save time and resources..." (P5).

It was noted that commitment to change was needed by all those involved in a situation, project or team. "...in a collaborative project there must be people who have the best knowledge of the matter, everyone must be given the opportunity to develop" (P2). Open conversation, commitment to change and understanding are needed, because change is an ongoing process. "...the development starts from a general state of will, atmosphere. A willingness that you will do and you will see the client as a goal..." (P4).

The utilization of potential is also needed to develop collaboration. One participant said: "The starting point for you being able to really utilize knowledge is the utilization of potential in order to benefit clients" (P4). The importance of highlighting own knowledge and contribution to collaboration were also emphasized. Support is needed to facilitate the ability and opportunity of staff to contribute their knowledge during collaboration.

"...[Staff] need to experience that their care leader trusts them and what they do... that they get to feel that you appreciate their work... to further enable and recognize their own and subordinates' potential and make it visible for the teams... it is part of the care leader's role to promote each professional's skills. And what benefit it has for the team" (P3).

\section{Purposeful action, enablement of developmental work and boundary-crossing work}

Purposeful action and the enablement of developmental work were highlighted.

"The fact that it is possible to develop collaboration together with the staff... that you give the opportunity to delve into the matter... from the organization the goals and the opportunity to be able to prioritize collaboration [in]to your own work... Support to enable cooperation" (P2).

The participants even experienced that boundary-crossing work was needed to increase understanding for other sectors and the skills inherent to other sectors. "... we work in our own compartments... we must become aware of what is going on in different units in order to be able to guide residents in the municipality" (P5). "...you should get away from these sectors... where you 'live' especially in larger organizations" (P4). Engaging in boundary-crossing work requires the ability to "step outside" one's "comfort zone". "...a leap into the unknown can often give rise to resistance at first... until you realize that it works and that it is a good thing" (P1).

The development of collaboration between different healthcare professions was considered to be beneficial for clients, staff and the organization. It was perceived to lead to better care and care quality for clients. Also, that effective collaboration allowed the "voice" of all parties to be heard and facilitated the more efficient management of work. "...for clients it is valuable to have an interprofessional team that 
takes care of their things" (P1). Another revealed: "... I see the collaboration between different healthcare professions [as being] important for clients' better care and quality assurance" (P4).

\section{Commitment of management, prioritization, structured action, justification and clear division of work}

The participants noted that the commitment of management and the organization were needed. Management and the organization must demonstrate openness and provide a clear picture of their expectations and goals for the development of collaboration. They even stated that care leaders lead by example and highlighted that staff can have difficulty developing collaboration if their care leaders do not support boundary-crossing work.

"Before there can be broader cooperation between different healthcare professions for staff it must [be] owned and be a goal for all care leaders, management and organization... it must be the organization's and management's view that such collaboration is realized and developed... until it also engages upper management and own care leaders" (P2).

Leadership plays an essential role in how development projects are presented and received. "...even that how you present this type of reforms... and how it then should be processed to get all professionals alongside so well that they understand the benefits of it... when everyone is involved in it it works" (P1).

Prioritization of the development of collaboration must occur for change to be possible. "...challenges occur naturally when resources are insufficient, in other words there is too much pressure so then it easily happens that things do not progress" (P1). The participants experienced that time was needed for change as well as the enablement of the prioritizing of collaboration in one's actions. "...it [collaboration] needs clear goals, purposefulness, prioritization, all vision far to the future, planned... it must be prioritized in the sequence" (P2).

Time, structured action and well-thought-out planning are needed to develop collaboration and collaborative processes.

"... it presupposes that everyone is clear about what the lodestar is, i.e., what we strive for and what the goal is. And the way there... You must in an open manner write out these steps and how the thought is that we achieve the goals" (P5).

Justification of why developing collaboration is important, including explanation of the new things collaboration can entail for one's work and for clients, is needed. The participants perceived that is important to be clear and certain that everyone understands collaboration in the same way and to have information about the development of collaboration visible for all. To facilitate the workload, all staff are needed in the development of collaboration as well as a clear division of work. 
"... I have such a perception that [the development of collaboration between different healthcare professions] does not really progress under its own flag but that there must be someone responsible for it. ... care leader or a named responsible person..." (P5).

\section{Discussion}

The aim of the study was to explore care leaders' experiences of collaboration between different healthcare professions in primary care. The importance of working physically close to one another, the inclusion of clients and understanding clients' individual needs emerged from the findings. Working physically close to each other can be seen to promote effective collaboration between different healthcare professions. Having the opportunity to engage in physically close interaction promotes a functional collaboration and enables the exchange of information. This is in line with previous research, in which effective collaboration between different healthcare professions has been shown to require effective interaction between both healthcare professionals and patients as well as between healthcare professionals from different healthcare professions (21). Synergy, interdependence and interaction between team members form the basis for interprofessional collaboration, where each member has special expertise and work must occur in close interaction to realize active communication and enable a good exchange of information (13). Geographical constraints, insufficient time for information exchange and high clinical requirements have been shown to hinder collaboration between different healthcare professions by negatively affecting the availability of team members $(14,13,8,10)$.

The inclusion of clients and understanding clients' individual needs were also seen as being central to promoting collaboration. To take client's diverse needs into consideration on a broader level, a holistic view of clients is required. In primary care, clients' care needs are varied and multifaceted, and such complex patient cases require broader competence and intervention. Researchers have found that because people are different, healthcare professionals should employ a holistic perspective and take into account each client's physical, mental, social, cultural and spiritual needs (29). This can be compared with person-centered care, in which a holistic view is also important (8) and the person in need of care is placed at the center of care and included in care decisions and processes to the extent possible (30). Including patients in own care not only increases understanding of clients' and clients' families' needs but also staff's awareness that their actions have consequences for individuals (8). Person-centered care allows clients the opportunity to influence and take responsibility for their care, which leads to better collaboration, more efficient self-care and reduced costs linked to fewer care visits (30). Person-centered care is to be desired, and in healthcare systems a focus on its development, where it is achieved through interprofessional teams, should be implemented (14).

The importance of a quick flow of communication, participation and a common approach to effective collaboration between different healthcare professions also emerged from the findings. The quick and functional flow of communication between different actors is important for the sharing of knowledge and information. This is in line with previous research, in which it has been found that care becomes more complex and specialized, more and more effective communication and collaboration are required to be 
able to offer patients the best possible care (10). Communication is a key element of effective collaboration (14) and involves regular negotiation and interaction between team members (12). A lack of communication between healthcare professionals has been shown to cause a lot of patient injury and errors $(10,2)$. The participants in this study even highlighted the participation and inclusion of all parties as leading to participation and thereby promoting collaboration; caregivers feel like important players in a larger context when collaboration is allowed. In previous research, collaboration has been shown to encompass different abilities and expertise: a way of working where the goal is to achieve common goals for patients and where the team's coordination of perspectives enables each member to contribute own knowledge to ultimately form a greater whole (10). Each professional group in an interprofessional team is unique and should receive recognition for providing a complementary contribution to the process (18). The participants in this study highlighted a need for a common approach, perceiving that such would facilitate interprofessional collaboration. This can be compared to ensuring that team members have a common understanding of a situation and work toward the same goals in care (10).

The importance of the inclusion of other professions and sectors and non-hierarchical work even emerged from the findings. A need for the inclusion of various other professions and sectors in the form of collaboration was revealed. The participants in this study stated that several professions and sectors should be included in collaboration, noting a need for larger teams and the use of other professions' and sectors' expertise. This is in line with previous research, where it has been shown that a need for interprofessional collaboration exits because health-related problems and needs are becoming so increasingly complicated and multifaceted that a single professional group can no longer meet clients' needs (2). Several experts are needed to identify problems and ponder possible solutions, therefore an interprofessional team should include several healthcare professionals from different professions (5). Caregivers from several different professions improve a team's performance, are more efficient and enable a more comprehensive assessment from different perspectives, thereby leading to better results $(13,14)$. The importance of non-hierarchical work was particularly highlighted by the participants in this study, because such was perceived to provide an opportunity for staff to be involved and subsequently promote collaboration. Researchers have found that hierarchical structure in healthcare has negative consequences for team communication and collaboration $(8,13,10)$ and has a negative impact on patient outcomes and person-centered care (14). Interprofessional collaboration has been described as a problem-focusing process where healthcare professionals from different disciplines work together within a non-hierarchical structure for a common goal (18). Hindering effective communication, trust and respect, hierarchy can occur both within an organization or a team itself (14). It should be ensured that team members have a common understanding of a situation and work towards the same goals in care (10). Interprofessional teams have non-hierarchical structures, where leadership roles are allocated to team members in relation to care needs, ensuring that the client and client's family are at the center of overall goals that are based on their descriptions and expectations of care (14).

The importance of having capacity for interaction and cooperation, respect for others' knowledge, commitment to change and the utilization of potential also emerged from the findings. The capacity for interaction and cooperation is needed to develop understanding of the importance of teamwork and thus 
collaboration (cf. 18). The differences that exist between disciplines and their associated educational programs affects how professionals understand others' roles, responsibilities and priorities and can lead to conflicts between occupational groups and hinder interprofessional collaboration (10). Most healthcare professionals have not learned how to work in interdisciplinary and interprofessional teams during training, therefore the development of skills in conflict resolution and holding regular team meetings in which communication skills are focused on can inhibit misunderstandings (14). The participants in this study strongly emphasized understanding and respect for others' knowledge as well as mutual trust between professionals (cf. 13) as contributing to the development of collaboration. Working collaboration involves team members supporting and trusting one another (c.f. 5,13 ), where mutual respect strengthens each member's value, regardless of discipline, and contributes to a better work environment (13). The participants in this study also experienced that open conversation, commitment to change and understanding were needed by all those involved in a situation, project or team, because change is an ongoing process. To realize effective collaboration, the continuous development of the collaboration is needed (21); the result is linked to how committed the team members are to the collaboration (5). The commitment of staff to interprofessional collaboration is increased when they are given the opportunity to participate in the process, are mutually committed to the collaboration and are supported (18). Time for reflection and mutual learning in teams must be given (15), because reflection allows a team to evaluate completed processes and outcomes in order to continue to develop their activities (5).

The importance of purposeful action, enablement of developmental work and boundary-crossing work also emerged from the findings. The participants revealed a need to work in a boundary-crossing manner and increase understanding for other sectors and the skills inherent to other sectors. This is in line with previous research, in which collaboration was shown to be needed beyond the team itself (1).

Interprofessional collaboration has even been recommended as a comprehensive approach whereby care teams can ensure person-centered care by combining skills, experience and knowledge (13). The aims underlying interprofessional collaboration is to ensure a responsive and integrated approach to care with a focus on clients' needs (19) and that team members have a common understanding of a situation and the common goal (10).

Lastly, the importance of the commitment of management and the organization, prioritization, structured action, justification and clear division of work emerged from the findings. The participants perceived that management and the organization must demonstrate openness, provide a clear picture of their expectations and goals. This is also in line with previous research; organizational support and expectations of collaboration are crucial for a functioning team (13). People in leading roles at group and higher levels need support (10), and administrative support in the form of showing commitment to quality improvement, innovation and effective implementation of change are also needed (13). Functional interprofessional collaboration requires decision-makers, care managers, team leaders and team members to understand the importance of collaboration (1) and management's support and understanding of practice (15). The participants in this study noted that the development of collaboration 
must be prioritized in order for change to be possible at all and that time, well-thought-out planning, structured action and a clear division of work and areas of responsibility were needed (cf. 31).

Other researchers have found that to provide comprehensive healthcare services and ensure fair access to services, equality, participation, planning and evaluation, a primary care team that includes several healthcare professions with a collective identity based on common ideals is needed (24). Some of the most common barriers to effective collaboration are linked to role boundary conflicts or the lack of clear role distribution and/or division of responsibilities $(12,16,11,14,13)$. This is about not understanding others' roles and importance within interprofessional teams (16). Communication problems can lead to problems with coordination, and complex work requires the division of labor, coordination, integration and delegation (11).

Strengths and limitations

More participants and men participating in the study could have led to somewhat different results. Furthermore, more variation via the inclusion of different healthcare sectors could have led to different results and may limit the generalizability and transferability of the findings. However, the number of participants was considered sufficient because data saturation was considered to be achieved. One strength is that all participants had experience of collaboration between different healthcare professions. Others are that the researchers discussed and participated in the outlining of the study design, interview guide and analysis process in close collaboration, and the second researcher was an experienced researcher in qualitative methods. Descriptive quotations have been used to answer the requirements of reliability in the results. To strengthen reliability, the analysis steps have been described throughout. The results are considered to be able to help illuminate understanding of collaboration between different healthcare professions and care leaders' experiences of collaboration between different healthcare professions in primary care.

\section{Conclusion}

Care leaders experience the development and implementation of effective collaboration between different healthcare professions to be important and necessary in primary care. Factors considered to promote interprofessional collaboration are physically close interaction, inclusion of clients, understanding clients' individual needs, quick flow of communication, participation and common approach, inclusion of other professions and sectors, and non-hierarchical work. Factors important to the development of collaboration are capacity for interaction and cooperation, understanding and respect for others' knowledge, commitment to change, utilization of potential, purposeful action, enablement of developmental work, boundary-crossing work, commitment of management and the organization, prioritization, structured action, justification and clear division of work and responsibility. A focus on collaboration between different professions in other healthcare sectors could be included in future research. 


\section{Declarations}

\section{Ethics approval and consent to participate}

Good scientific practice has been followed during the course of this research, and it has been conducted in accordance with the guidelines for the Finnish National Board on Research Integrity TENK (2012). One of the researchers contacted those care leaders recommended for participation in the study by email and telephone. The care leaders received both oral and written information about the study purpose, voluntary participation, confidentiality and the intention to publish the study results. Informed consent was obtained from the study participants. Ethical approval was obtained (January 4,2021) from the ethical committé at the joint municipality where the interviews were conducted.

\section{Consent for publication}

The participants provided their informed consent regarding the intention to publish the study results.

\section{Data availability}

The data that support the findings of this study are available from the authors but restrictions apply to the availability of these data, which were used under license for the current study, and so are not publicly available. Data are however available from the authors upon reasonable request and with permission of an ethical approval to take part of the dataset. For more information contact: jessica.hemberg@abo.fi

\section{Competing interests}

The authors declare that they have no competing interests.

\section{Funding}

No funding has been received for the undertaking of this study and/or preparation of this manuscript. The authors declares that there is no conflict of interest.

\section{Authors' contributions}

JN contributed to the study design, the data collection and the analysis, as well as to the interpretation of the analysis and drafting the manuscript. JH contributed to the study design, the interpretation of the analysis, as well as drafting the manuscript. Both authors read and approved the final manuscript. 


\section{Acknowledgements}

None.

\section{References}

1. Mulvale G, Embrett M \& Razavi S D. 'Gearing up' to improve interprofessional collaboration in primary care: a systematic review and conceptual framework. BMC Fam Pract, 2016;17:83-83. doi:10.1186/s12875-016-0492-1

2. Tuomela K, Heikkilä K, Haapanen H, Kortekangas-Savolainen O \& Salminen L. Moniammatillinen oppiminen yhteistyöosaamisen edistäjänä terveydenhuollossa. Hoitotiede, 2017;29:264-275

3. Gilbert J H V, Yan J \& Hoffman S J A WHO report: Framework for Action on Interprofessional Education and Collaborative Practice. J of Allied Health, 2010;39:196.

4. Government Ministery. Participatory and competent Finland - a socially, economically and ecologically sustainable society 2019. (In Finnish: Osallistava ja osaava Suomi - sosiaalisesti, taloudellisesti ja ekologisesti kestävä yhteiskunta). (Government publications 2019:

23). https://julkaisut.valtioneuvosto.fi/bitstream/handle/10024/161931/VN_2019_31.pdf? sequence=1\&isAllowed=y Accessed 15 November 2020.

5. Mönkkönen K, Kekoni T \& Pehkonen A. Interprofessional cooperation: effective interaction in the social and health fields. (In Finnish: Moniammatillinen yhteistyö: vaikuttava vuorovaikutus sosiaalija terveysalalla.) Gaudeamus, 2019.

6. Isoherranen K. Interprofessional cooperation (In Finnish: Moniammatillinen yhteistyö.) Porvoo: WSOY, 2004.

7. Husebø S E \& Akerjordet K. Quantitative systematic review of multi-professional teamwork and leadership training to optimize patient outcomes in acute hospital settings. $\mathrm{J}$ of Adv Nurs, 2016;72:2980-3000. doi: 10.1111/jan.13035.

8. Cutler S, Morecroft C, Carey P \& Kennedy T. Are interprofessional healthcare teams meeting patient expectations? An exploration of the perceptions of a patients and informal caregivers. J Interprof Care, 2019;33:66-75. doi:10.1080/13561820.1514373.

9. Pelzang R. Time to learn: understanding patient-centered care. British J of Nurs, 2010;19:912-917. doi: 10.12968/bjon.2010.19.14.49050

10. Weller J, Boyd M \& Cumin D. Teams, tribes and patient safety: overcoming barriers to effective teamwork in healthcare. Postgraduate Medical J, 2014;90:149-154. doi:10.1136/postgradmedj2012-131168

11. Rosen M A, DiazGranados D, Dietz A S, Benishek L E, Thompson D, Pronovost P J \& Weaver S J. Teamwork in Healthcare: Key Discoveries Enabling Safer, High-Quality Care. The American Psychologist, 2018;73:433-450. 
12. Reeves S, Pelone F, Harrison R, Goldman J \& Zwarenstein M. Interprofessional collaboration to improve professional practice and healthcare outcomes. Cochrane Database Syst Rev, 2017;6:1-38. doi: 10.1002/14651858.CD000072.pub3

13. Youngwerth J \& Twaddle M. Cultures of Interdisciplinary Teams: How to Foster Good Dynamics. J of Palliat Medicine, 2011;14:650-654.

14. Twaddle M. Teamwork - The New Way. Health Progress, 2012;13-17.

15. Sørensen M, Stenberg U \& Garnwidner-Holme L. A Scoping Review of Facilitators of MultiProfessional Collaboration in Primary Care. Intern J of Integrated Care, 2018;18:13-13.

16. Brown J, Lewis L, Ellis K, Stewart M, Freeman T R \& Kasperski M J. Conflict on interprofessional primary health care teams - can in be resolved? J of Interprof Care, 2011;25:4-10.

17. Fridén C \& Olsson C. Interprofessional collaboration in primary care. (In Swedish: Interprofessionellt samarbete i primärvården). Fysioterapi, 2018;36-42.

18. Petri L. Concept Analysis of Interdisciplinary Collaboration. Nurs Forum (Hillsdale), 2010;45:73-82. doi: 10.1111/j.1744-6198.2010.00167.x

19. Nummela O, Juujärvi S \& Sinervo T. Competence needs of integrated care in the transition of health care and social services in Finland. Intern $\mathrm{J}$ of Care Coordination, 2010;22:36-45. doi.org/10.1177/2053434519828302

20. Chandratilake M. From the professionalism of a profession to the professionalism of a multiprofessional team. Medical Education, 2014;48:345-347. doi:10.1111/medu.12318

21. van Dijk-de Vries A, van Dongen J J J \& van Bokhoven M A. Sustainable interprofessional teamwork needs a team-friendly healthcare system: Experiences from a collaborative Dutch programme. $J$ of Interprof Care, 2017;31:167-169. doi: 10.1080/13561820.2016.1237481

22. Lloyd J V, Schneider J, Scales K, Bailey S \& Jones R. Ingroup identity as an obstacle to effective multiprofessional and interprofessional teamwork: findings from an ethnographic study of healthcare assistants in dementia care. J of Interprof Care, 2011;25:345-351. doi: 10.3109/13561820.2011.567381

23. Miller C J, Kim B, Silverman A \& Bauer M S. A systematic review of team-buildning interventions in non-acute healthcare settings. BMC Health Serv Res, 2018;18:146-146. doi:10.1186/s12913-0182961-9.

24. Bentley M, Freeman T, Baum F \& Javanparast S. Interprofessional teamwork in comprehensive primary healthcare services: Findings from a mixed methods study. $J$ of Interprof Care, 2018;32:274-283. doi: 10.1080/13561820.2017.1401986

25. Guraya S Y \& Barr H. The effectiveness of interprofessional education in healthcare: A systematic review and meta-analysis. The Kaohsiung $\mathrm{J}$ of Medical Sciences, 2018;34:160-165.

26. Gary J C, Gosselin K \& Bentley R. Health science center faculty attitudes towards interprofessional education and teamwork. J of Interprof Care, 2018;32:231-234.

doi:10.1080/13561820.2017.1376626 
27. Graneheim U H \& Lundman B. Qualitative content analysis in nursing research: concepts, procedures and measures to achieve trustworthiness. Nurse Education Today, 2004;24:105-112.

28. Finnish Advisory Board on Research Integrity. Guidelines for responsible conduct of research and procedures for handling allegations of misconduct in Finland. 2012. http://www.tenk.fi/sites/tenk.fi/files/HTK_ohje_2012.pdf Accessed 25 October 2020.

29. Imborn M, Åsbrink B \& Hjelm K. Health care and social work 1 (In Swedish: Vård-och omsorgsarbete 1.) Stockholm: Sanoma Utbildning AB, 2017.

30. Udo C. Treatment in health and care, values. 2020. (In Swedish: Bemötande i vård och omsorg, värdegrund) https://www.vardhandboken.se/arbetssatt-och-ansvar/bemotande-i-vard-ochomsorg/bemotande-i-vard-och-omsorg-vardegrund/personcentrerad-vard/ Accessed 12 November 2020.

31. Salmela S, Eriksson K, Fagerström L. Leading change: a three-dimensional model of nurse leaders' main tasks and roles during a change process. J Adv Nurs, 2012;68:423-433. doi:10.1111/j.13652648.2011.05802.x. 